\begin{tabular}{c} 
International Journal of Engineering \& Technology, $7(4)(2018) 4683-4690$ \\
International Journal of Engineering \& Technology \\
SPC \\
Website: $\begin{array}{c}\text { www.sciencepubco.com/index.php/IJET } \\
\text { doi: } 10.14419 / \text { ijet. } v 7 \text { it.15407 } \\
\text { Research paper }\end{array}$ \\
\hline
\end{tabular}

\title{
Modeling of dynamic fracture mechanism in rock masses due to wave propagation
}

\author{
Mirvat Abdallah $1 *$, Fatima Haidar ${ }^{2}$ \\ ${ }^{1}$ Assistant Professor at Rafik Hariri University, Mechref, Damour - Lebanon \\ ${ }^{2}$ Master's Student at Lebanese university, Faculty of Engineering, 3rd branch, Hadath - Lebanon \\ *Corresponding author E-mail: abdallahma@rhu.edu.lb
}

\begin{abstract}
Finding a new oil well is a stimulating experience at all levels, however, it's only an important milestone on the road towards exploiting oil and gas. When it comes to well drilling, the condition of the ground that surrounds the oil plays a major role. While there are many factors that dictate the success of exploring and drilling wells, porosity and permeability of the surrounding stone are some of the most important components.

This paper focuses on the effective way to increase the porosity and the permeability of the rock using explosives without damaging the rock. In order to reach our aim, a numerical simulation was conducted. In fact, a 2D distinct element code was used, and 4 models were constructed; in each model the number of explosives increase while the blast load per explosive decreases.

The dynamic stresses, and velocity vectors of the wave propagation were analyzed to evaluate the behavior of rock masses in each model. Moreover, a grid of history points was studied in order to compare the results and find the most suitable method to increase the crack propagation, therefore, the porosity and permeability along the rock masses, without damaging it.
\end{abstract}

Keywords: Blast Wave; Dynamic Fracture Mechanism; Fracture Propagation; Numerical Modeling.

\section{Introduction}

Lebanon is the Levant's most recent candidate to join the rank of Middle East gas producer. In fact, on December 14, 2017, the Lebanese Council of Ministers approved the awards of two exclusive petroleum licenses for exploration and production in blocks 4 and 9 for the consortium composed of Total S.A, Eni International BV and JSC Novatek. Drilling activities will start in 2019 [10].

For more than 15 years now, documented news about Lebanon sitting on an offshore wealth of oil and gas resources have actively encouraged multinationals to move towards this sector. Huge investments in this sector promise to create a new resource for Lebanon through the development of large-scale drilling and extraction projects.

As Lebanon moves closer to extracting offshore and onshore oil and gas resources, and in order to reduce the financial cost and risk of exploration, relevant information about the reservoir, the source rocks, and the trapping mechanisms responsible for the petroleum deposit is primordial.

Two of the most important parameters to determine about the reservoir are its porosity and its permeability, because they regulate the amount and rate of production of oil and natural gas. It is very important to increase the porosity of the rock mass in order to increase the productivity of a well.

Porosity is increased through fracturing, so if the porosity and the permeability of the reservoir rock are inadequate for profitable recovery of oil and gas, there are various means by which these properties may be artificially increased. Explosives set off at the bottom of the hole may fracture the reservoir rock and open it up. Large quantities of acid may be introduced through the well in order to dissolve additional and larger openings in calcareous reservoir rocks such a limestone, dolomites, or lime-cemented sandstones. Acidizing also increases the area of exposed reservoir rock surface in the vicinity of the well so that the oil can "bleed" more rapidly out of the reservoir rock pores into the well. "Hydrafracturing" [9] is a process whereby porosity and permeability of the reservoir are increased by plumbing a soluble gel into the reservoir under tremendous pressure. The gel can then be dissolved and pumped out again [9]. Water also may be pumped down certain wells in or around a field in order to "flush" the oil toward other producing wells.

Fragmentation produced by explosive blasting is an extremely complex process involving the nucleation and propagation of myriad micro cracks that finally coalesce, breaking the rock into fragments [14]. In fact, the fragmentation is affected by inherent properties of the material, loading conditions, geometry such as the existence of free boundaries and discontinuities, etc. Hence, most blast models, today, depend on a series of models and equations that are based on empirical or semi-empirical formulas. The processes of rock fracture and fragmentation around a borehole are strongly dependent on the parameters of the explosive detonation and the dynamic response of rock, as demonstrated in field experiments [15]; therefore, we found it essential to implement both experimental and numerical studies. In fact, theoretical study on rock blasting is relatively difficult due to the complicated process of blasting itself and to the convoluted response of rocks. At the present time, the focus of theoretical study has been, mainly, on the propagation of the preexisting cracks under the gas pressure loading, and lesser attention has been paid to initial cracks resulting from stress wave loading $[15-16]$.

In rock blasting, it is generally agreed that two types of loadings, stress wave (or shock wave) loading and explosion gas pressure 
loading, operate on the surrounding rock. The stress wave loading arises out of detonation of the explosive column in a borehole. Generally, the detonation pressure exerted on the borehole wall at the moment of initiation can exceed $10 \mathrm{GPa}$. This high pressure on the borehole wall sets off a shock wave in the adjacent rock mass, but it soon decays to a high amplitude stress wave propagating at the velocity of longitudinal wave in the rock mass. It is immediately followed, even if at a much-reduced velocity, by the longer duration gas pressure loading. The stress wave initiates cracks around the borehole, and the gas penetrates into these cracks and causes their further extension and propagation. Thus, both loadings are essential in the process of cratering and benching [15].

Fragmentation depends largely on the dynamic fracture process, which plays an important role mainly in controlling the number of fractures produced and fracture propagation direction [4]. In order to control fragmentation, one has to consider the fracture processes associated with material properties and the external force. To reveal the fragmentation mechanisms, it is first necessary to develop an appropriate method of analysis, which simulates the progressive fracture of rock leading to failure and allows prediction of rock fragmentation under various loading conditions.

\subsection{Explosives pressure}

The importance of shock and gas in fragmentation has been debated for the last 50 years [13]; however, recent studies tend to support the view that stress waves are responsible for the development of a damage zone in the rock mass and for the subsequent fragment size distribution, while the explosive gases are important in separating the crack pattern and in throwing the fragments [13].

On one hand, the magnitude of shock wave pressure is a function of the velocity of detonation, density and charge's ingredients [6]. The current work adopts the empirical formula proposed by Lopez [7], which can adequately estimate blast load:

$$
\mathrm{PD}=432 \times 10^{-6} \frac{\rho_{\mathrm{e}} \mathrm{VD}^{2}}{1+0.8 \rho_{\mathrm{e}}}
$$

Where, PD is the blast pressure (MPa), $\rho_{\mathrm{e}}$ the explosive density $\left(\mathrm{gr} / \mathrm{cm}^{3}\right)$ and VD the velocity of detonation $(\mathrm{m} / \mathrm{s})$.

Gas pressure is usually considered as half of the blast pressure:

$$
\mathrm{PE}=\frac{1}{2} \mathrm{PD}
$$

If the diameter of the explosive is equal to blasthole's diameter, i.e. coupled detonation, then there is no gap between blasthole and explosive and the related pressure can be calculated as follows:

$$
\mathrm{PW}=\mathrm{PE} \cdot\left(\frac{\mathrm{r}_{\mathrm{h}}}{\mathrm{b}}\right)^{-\mathrm{qk}}
$$

Where $r_{h}$ is the radius of the hole $(\mathrm{mm}), \mathrm{b}$ the explosive radius $(\mathrm{mm}), \mathrm{k}$ the specific heat coefficient, and $\mathrm{q}$ the shape factor of explosive, which is equal to 2 for cylindrical charges and 3 for spherical charges [16].

On the other hand, applied dynamic pressure on blasthole's wall is a function of time due to the interaction between rock and generated shock wave. According to Starfield's equation [12], generated dynamic pressure on the wall, $\mathrm{P}(\mathrm{t})$, is a function of rock density $\rho_{\mathrm{r}}$, explosive density $\rho_{\mathrm{e}}, \mathrm{P}$-wave velocity $\left(\mathrm{C}_{\mathrm{p}}\right)$, velocity of detonation (VD) and PW. $\mathrm{P}(\mathrm{t})$ is calculated as follows:

$$
\mathrm{P}(\mathrm{t})=\mathrm{PW} \cdot \frac{8 \rho_{\mathrm{r} \cdot \mathrm{C}}}{\rho_{\mathrm{r}} \cdot \mathrm{C}_{\mathrm{p}}+\mathrm{VD} \cdot \rho_{\mathrm{e}}}\left[\mathrm{e}^{(-\mathrm{Bt} / \sqrt{2})}-\mathrm{e}^{(-\sqrt{2 \mathrm{Bt}})}\right]
$$

\subsection{Exploration overview}

Petroleum exploration has a long history in Lebanon. It started in the thirties of the last century when the French high commissioner, Henry de Jouvenel, issued a decision authorizing the excavation, extraction and exploitation of oil and metal reserves [1]. From that time until the seventies, several wells have been carried out in the Lebanese onshore. Some of them have been drilled up to $3000 \mathrm{~m}$ depth without actually finding oil. A first well was drilled in 1947 in Terbol, followed by another in Yuhmor in 1953. Both wells are in the Bekaa region and were drilled by Iraq Petroleum Company (IPC). Many tentative $(1953,1967)$ have proven the existence of oil and gas even though the quantity was considered inefficient. A total of seven wells have been drilled onshore between 1947 and 1967 [1].

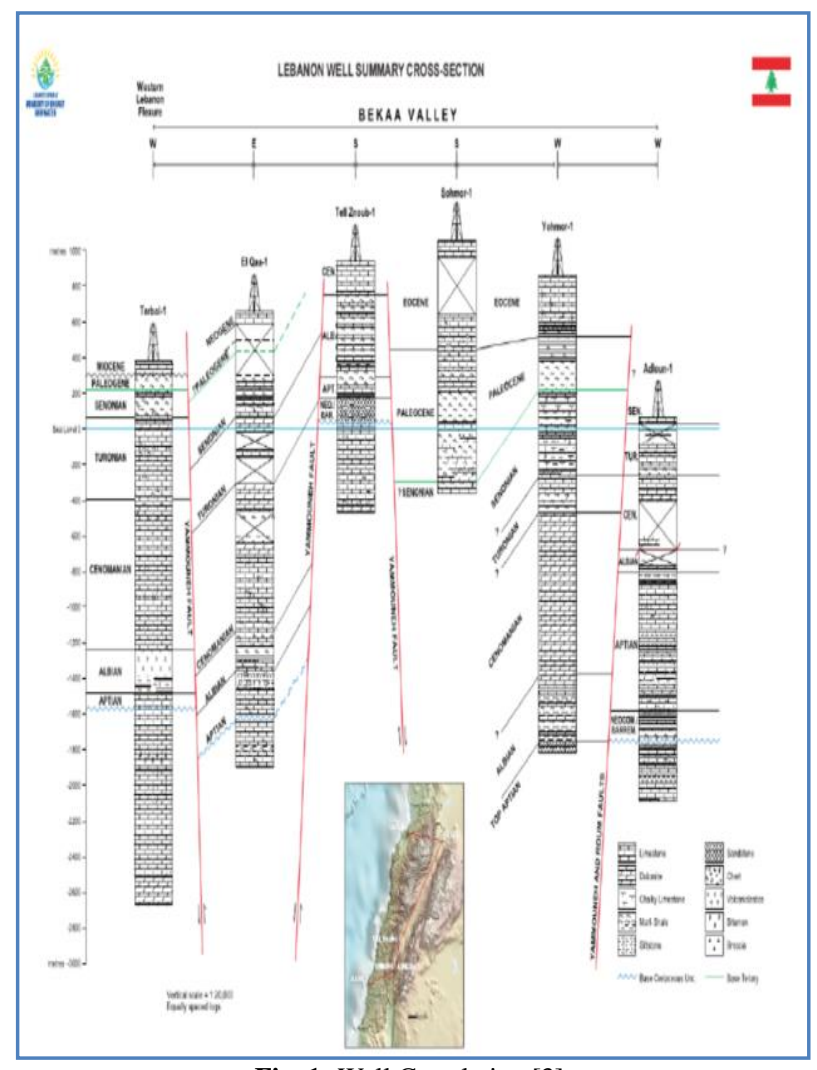

Fig. 1: Well Correlation [3].

Iraq Petroleum Company (IPC) in collaboration with Lebanese authority has studied these wells in terms of stratigraphy and hydrocarbon [8-11] as shown in figure 1 . Yohmor-1 well was drilled by Petroleum Lebanese Company (PLC) in 1953 (Figure 2). It reached TD in Aptian sandstones. The structure was similar to Terbol, an east-west trending anticline located in the south of the Bekaa Valley. Hydrocarbon shows were recorded in Senonian limestones, which gave PLC the confidence to drill four further onshore wells between 1960 and 1963 [1]. 


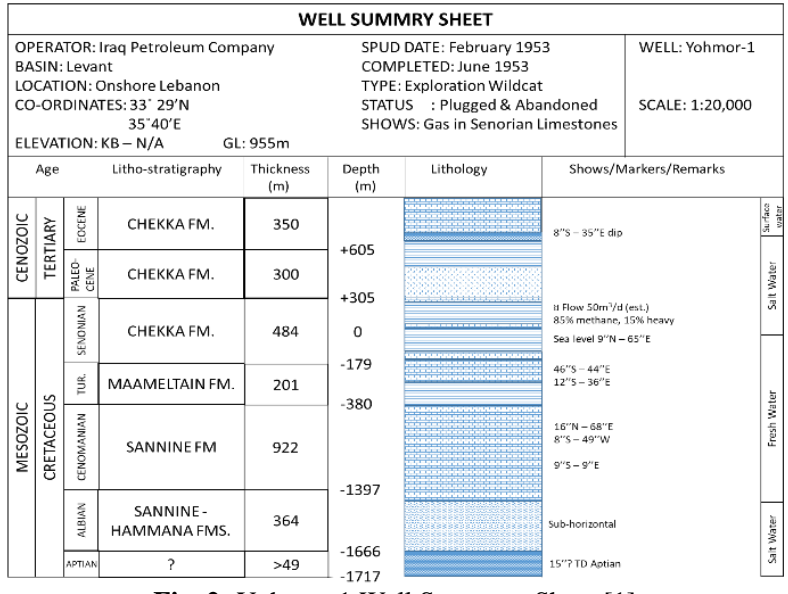

Fig. 2: Yohmor-1 Well Summary Sheet [1].

The most varied sequence of sediments is that which extends from Late Jurassic to the Middle Cretaceous and shows a considerable variety of limestones, sandstones, clays and volcanic ashes. The ashes tend to weather to a bright red or purple color and to give fertile soils. The only igneous rocks are basaltic flows and intrusions of a variety of ages. The only metamorphic rocks are confined to narrow bands around the edges of the intrusions.

\subsection{Concept of model}

Almost all the rocks in Lebanon are sedimentary rocks and most of these are pale limestones. Thus, the rock mass used in the model presented in this paper is limestone

\section{Numerical modeling using UDEC}

Numerical simulations are performed using the two-dimensional Universal Distinct Element Code (UDEC) software. UDEC simulates the response of discontinuous media subjected to either static or dynamic loading. The discontinuous medium is represented as an assemblage of discrete blocks. The discontinuities are treated as boundary conditions between blocks; large displacements along discontinuities and rotations of blocks are allowed. UDEC is based on a "Lagrangian" calculation scheme that is well-suited to model the large movements and deformations of a blocky system [12]. Homogeneous rock mass, $100 \mathrm{~m} \times 36 \mathrm{~m}$ width domain's geometry and non-reflecting boundaries were used as shown in figure 3 .

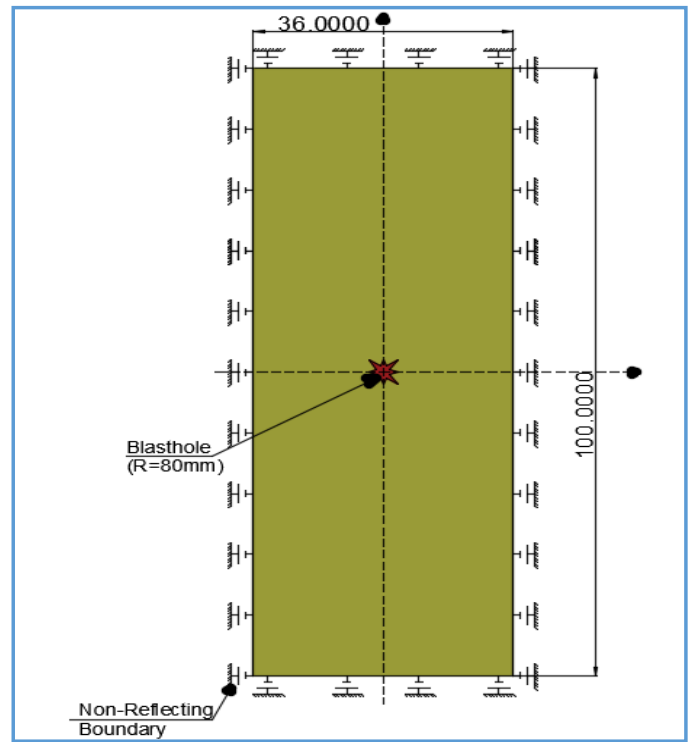

Fig. 3: Input Data - Numerical Modeling.
As mentioned above, the aim of this study is to analyze the increase in the porosity i.e. the well's productivity by using explosives without affecting the stability of the site and making a major damage of the rock mass.

Four models, which differ by the number of blasting points installed, were built. The distance between two consecutive blast points is $4 \mathrm{~m}(4 \mathrm{~m}=5 \mathrm{~d}$; $\mathrm{d}$ is the diameter of the blasthole).

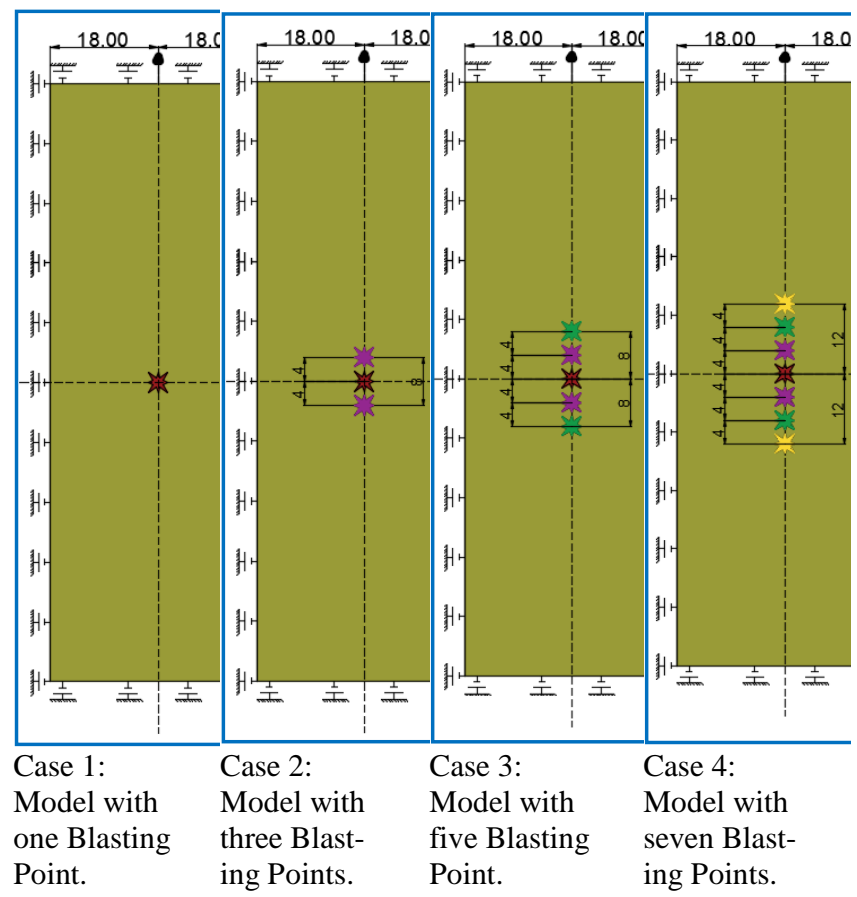

Fig. 4: Distribution of Blasting Points in Each Case.

\subsection{Mechanical properties of rock mass}

The mechanical properties of Limestone used are summarized in table 1 .

Table 1: Rock Mechanical Properties

\begin{tabular}{llllllll}
\hline $\begin{array}{l}\text { Param- } \\
\text { eter }\end{array}$ & $\begin{array}{l}\mathrm{P} \\
\left(\mathrm{kg} / \mathrm{m}^{3}\right)\end{array}$ & $\begin{array}{l}\mathrm{E} \\
(\mathrm{Gpa})\end{array}$ & $\mathrm{v}$ & $\begin{array}{l}\mathrm{c} \\
(\mathrm{MPa})\end{array}$ & $\begin{array}{l}\Phi \\
(\mathrm{deg})\end{array}$ & $\begin{array}{l}\Psi \\
(\mathrm{deg})\end{array}$ & $\begin{array}{l}\mathrm{T} \\
(\mathrm{Mpa})\end{array}$ \\
\hline Value & 2700 & 55 & 0.2 & 10 & 30 & 15 & 10 \\
\hline$\rho:$ density & & & & & & \\
E: Elastic Modulus & & & & & & \\
v: poisson's ratio & & & & & & \\
c: cohesion & & & & & \\
$\phi:$ friction angle & & & & & \\
$\psi:$ Dilation angle & & & &
\end{tabular}

\subsection{Explosives parameters}

The pressure of the explosive, as shown in equation 4 , is related to the density and velocity of detonation, four different densities of commercial explosives were used [5], as shown in table 2.

\begin{tabular}{llll}
\multicolumn{5}{c}{ Table 2: Explosives Parameters } \\
\hline $\begin{array}{l}\text { Case } \\
\text { No. }\end{array}$ & Model & $\begin{array}{l}\text { Density of Detonation } \\
\left(\mathrm{g} / \mathrm{cm}^{3}\right)\end{array}$ & $\begin{array}{l}\text { Velocity } \\
(\mathrm{m} / \mathrm{s})\end{array}$ \\
\hline 1 & 1 blasting point & 1.55 & 7000 \\
2 & 3 blasting points & 1.25 & 5000 \\
3 & 5 blasting points & 1 & 3500 \\
\hline 4 & 7 blasting points & 0.8 & 2500 \\
\hline
\end{tabular}

Pressures on borehole's wall using the equation 4 are calculated and shown in figure 5 . 


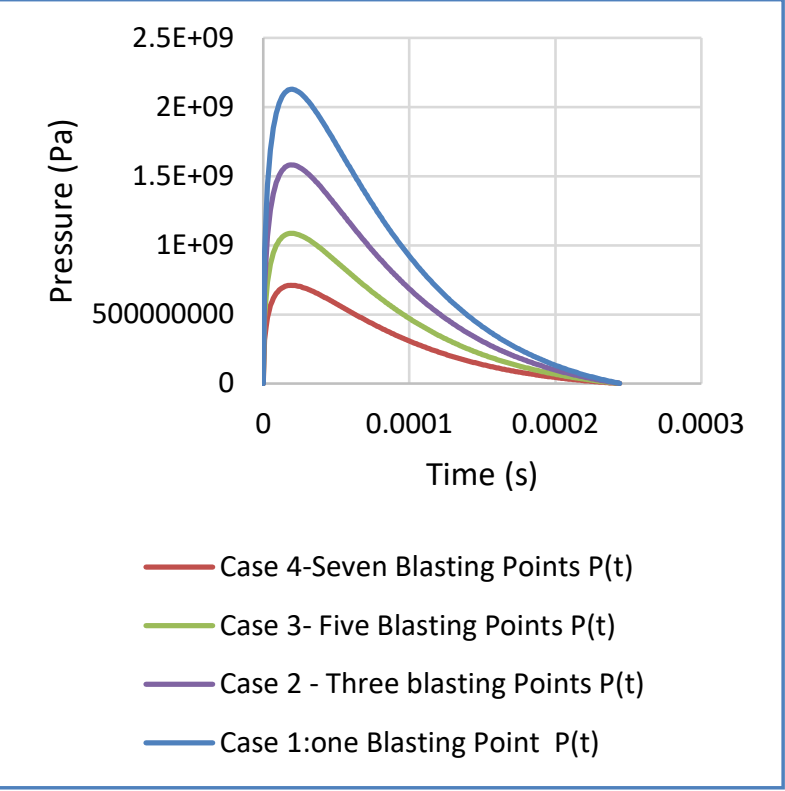

Fig. 5: Dynamic Pressure Applying on the Blasthole's Wall for the 4 Models.

\subsection{Timing}

The delay between two consecutive explosions is $1 \mathrm{~ms}$ as shown in the figure below in the case of 7 blasting points.

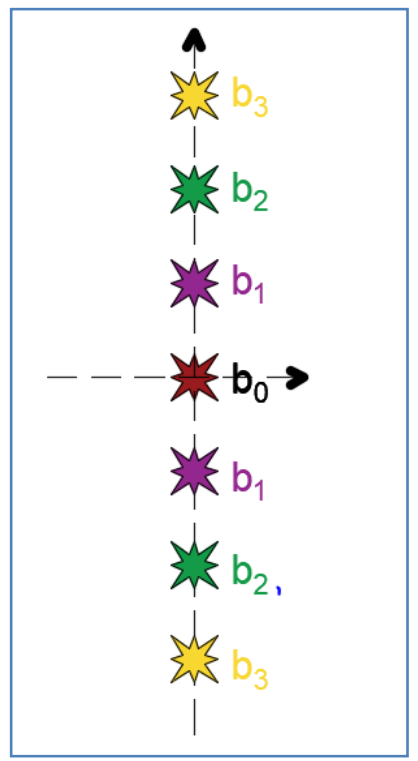

Fig. 6: A) Blasting Points Numeration.

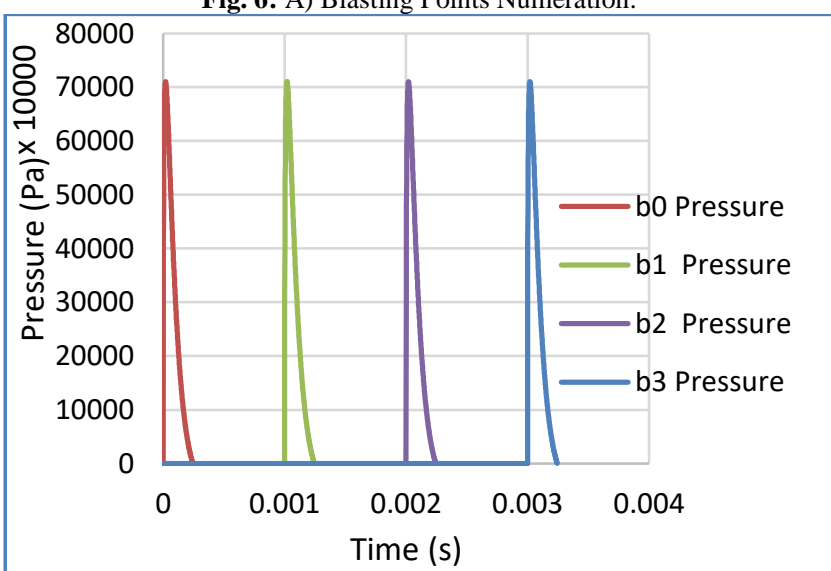

Fig. 6: B) Dynamic Pressure Applied on the Blasthole's Wall for the 7 Blastholes - Model Case 4.

\section{Results and discussions}

36 numerical simulations were performed, stress wave propagation in each model was registered and a conclusion was made.

\subsection{Stress wave propagation}

Figures 7, 8, 9 and 10 below show the stress wave propagation within different time steps for the $1^{\text {st }}, 2^{\text {nd }}, 3^{\text {rd }}$ and $4^{\text {th }}$ cases when one, three, five and seven blasting points were installed respectively into the rock mass domain.

Case 1: One Blasting Point

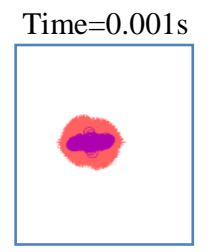

Time $=0.003 \mathrm{~s}$

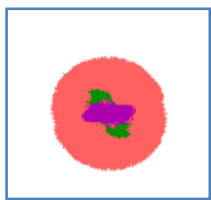

Time $=0.008 \mathrm{~s}$

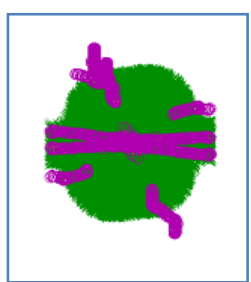

Time $=0.002 \mathrm{~s}$.

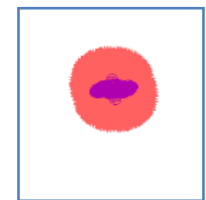

Time $=0.004 \mathrm{~s}$.

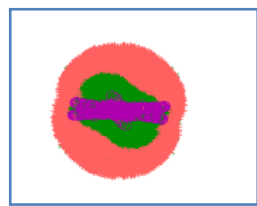

Time $=0.012 \mathrm{~s}$

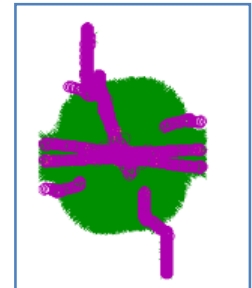

Fig. 7: A) Stress Wave Propagation in Different Time Steps - Case 1: One Blasting Point.

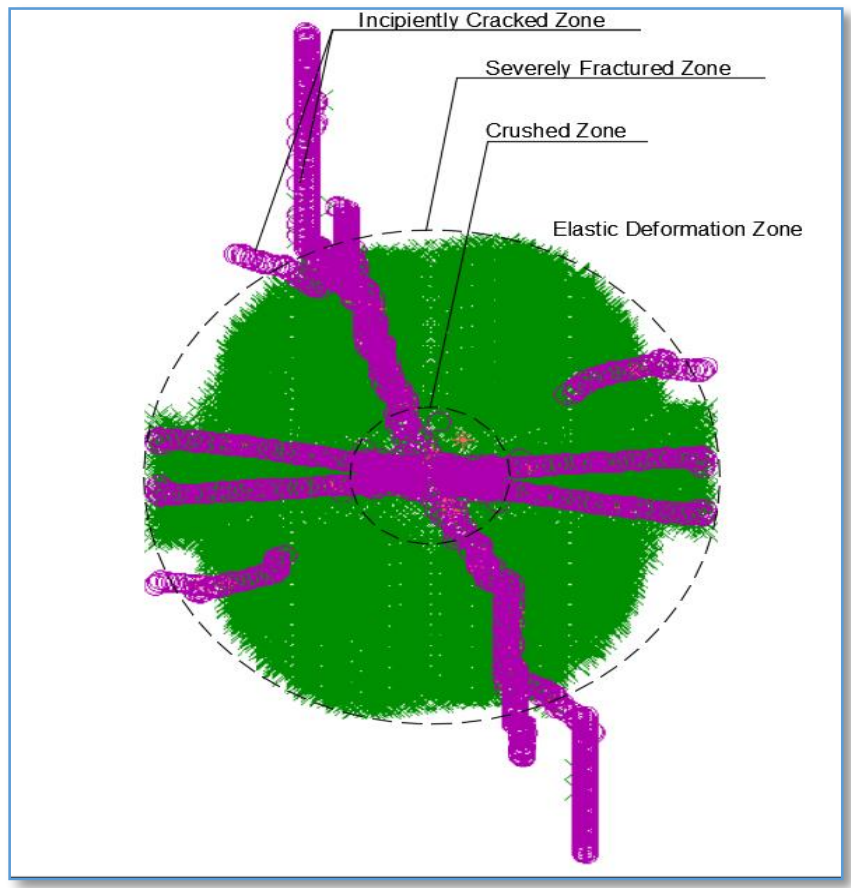

Fig. 7: B) Illustration of the Crushed Zone and Severely Fractured Zones Around Blasthole- Case 1: One Blasting Point. 
The diameter of damaged zone increases with time (Figure 7a), and due to the high radial compressive stresses near the borehole, an intense shear stress field develops near the borehole. In the shear failure zone, the rock is severely crushed. The crushed zone is followed by a severely fractured zone. The crack density in this zone is very high and the damage is severe. Beyond the severely fractured zone, there is the incipiently cracked zone. In this zone, the radial crack density is lower than that in the severely fractured zone. And the severely crushed zone is followed by the elastic deformation zone, when the explosive has no effect (Figure 7b).
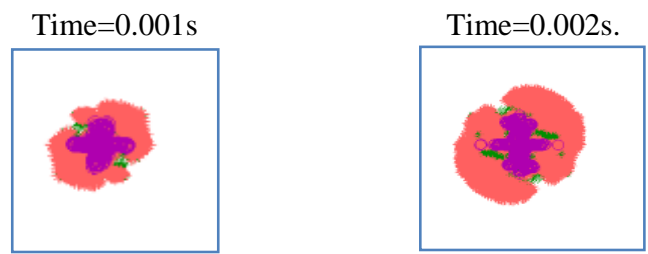

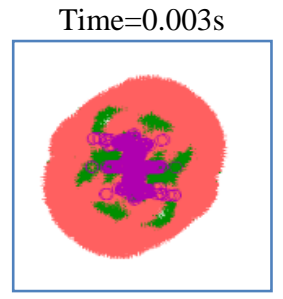

Time $=0.004 \mathrm{~s}$

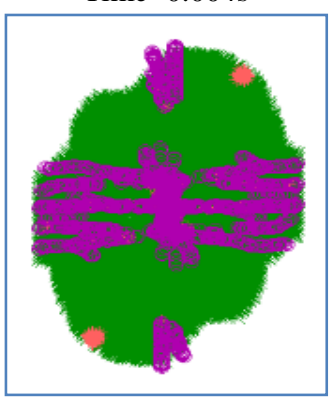

Fig. 8: A) Stress Wave Propagation in Different Time Steps - Case 2: Three Blasting Points.
Time $=0.008 \mathrm{~s}$.

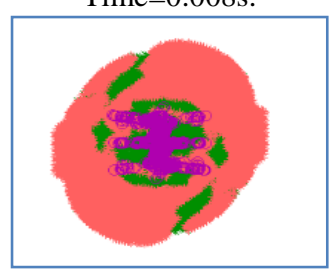

Time $=0.012 \mathrm{~s}$.

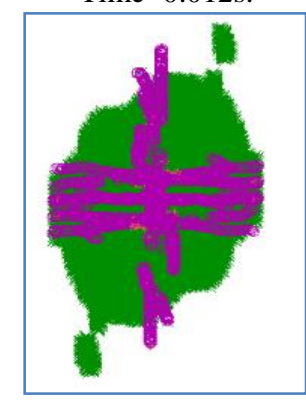

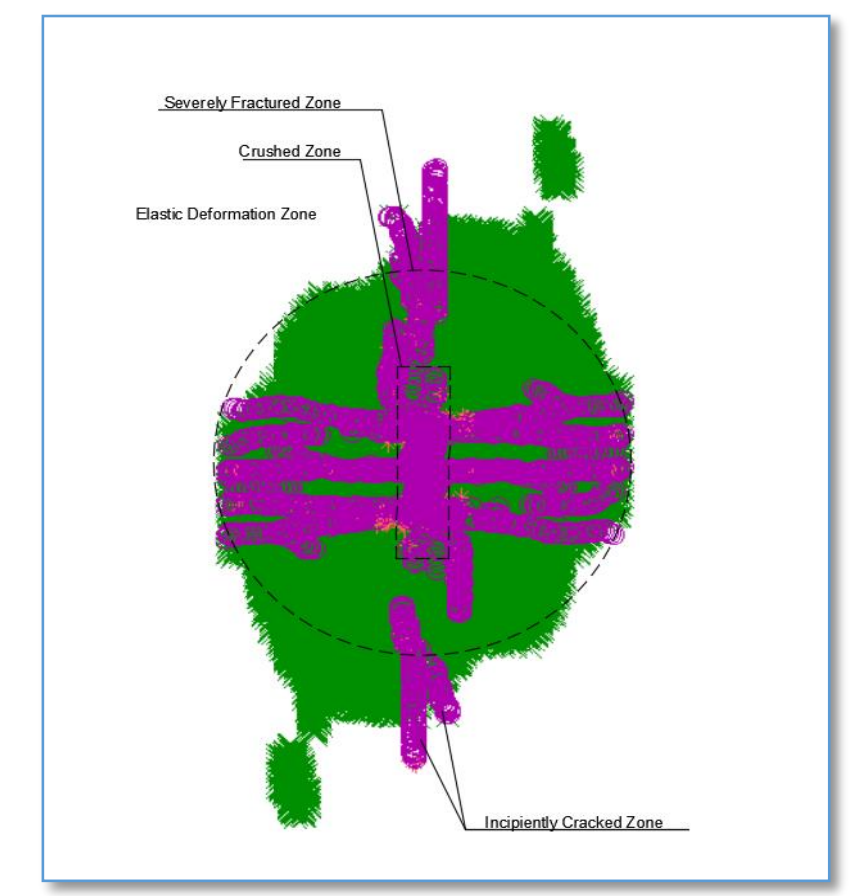

Fig. 8: B) Illustration of the Crushed Zone and Severely Fractured Zones Around Blasthole- Case 2: Three Blasting Points.

Same as case 1 , the diameter of damaged zone increases with time. The explosion of the $2^{\text {nd }}$ blasthole ( $4 \mathrm{~m}$ is the distance between the $1^{\text {st }}$ and $2^{\text {nd }}$ Blasting Points) is clearly shown at $0.002 \mathrm{~s}$ time-step (Figure 8a), the crushed zone develops along the line of blasthole, and the intensity of severely fractures zone increases (Figure 8b).
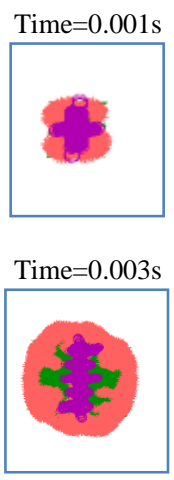

Time $=0.008 \mathrm{~s}$

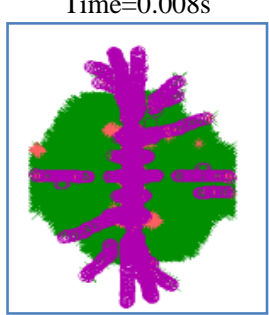

Time $=0.002 \mathrm{~s}$
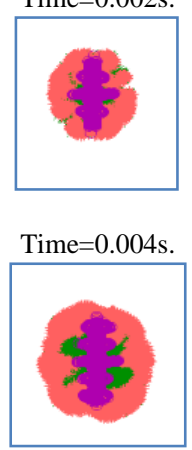

Time $=0.012 \mathrm{~s}$.

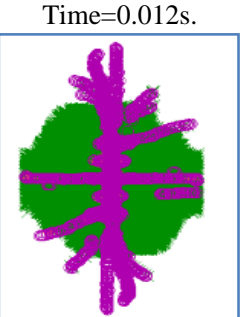

Fig. 9: A) Stress Wave Propagation in Different Time Steps - Case 3: Five Blasting Points. 


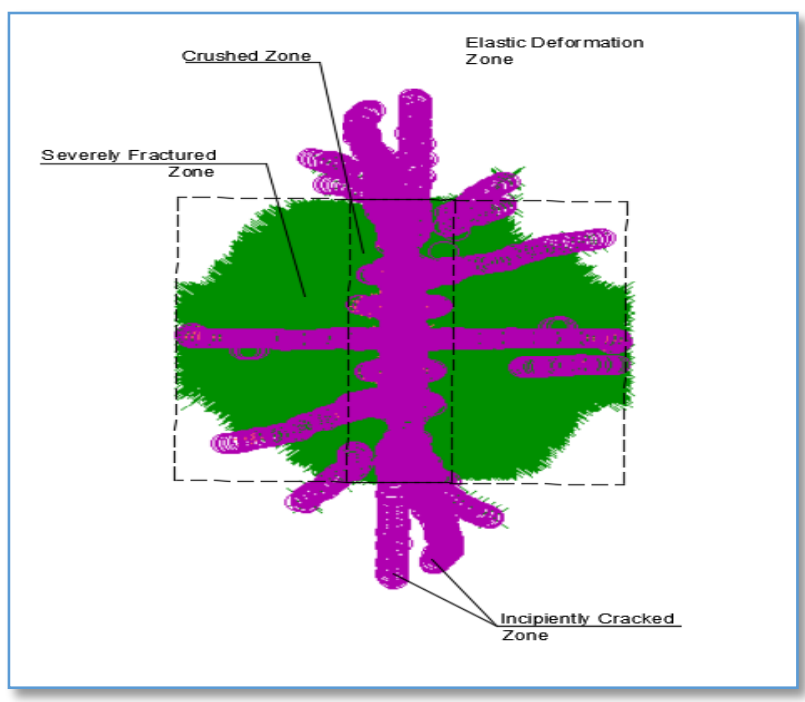

Fig. 9: B) Illustration of Crushed Zone and Severely Fractured Zones Around Blasthole- Case 3: Five Blasting Points.

In this case, the following remarks are noticeable:

1) The area of the damaged zone increases with time;

2) the propagation of the incipiently cracked zone is reduced;

3) The crushed zone is smaller than that observed in case 2.
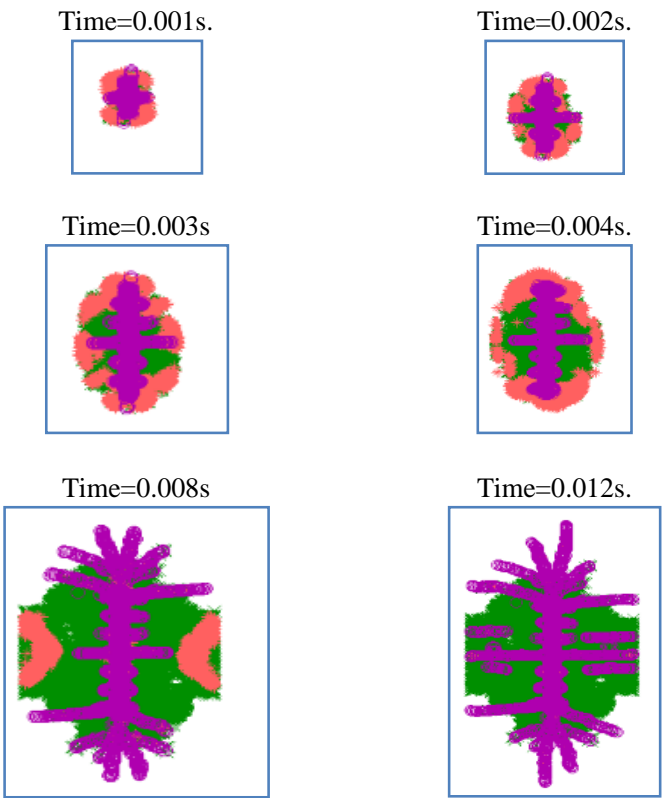

Fig. 10: A) Stress Wave Propagation in Different Time Steps - Case 4 Seven Blasting Points.

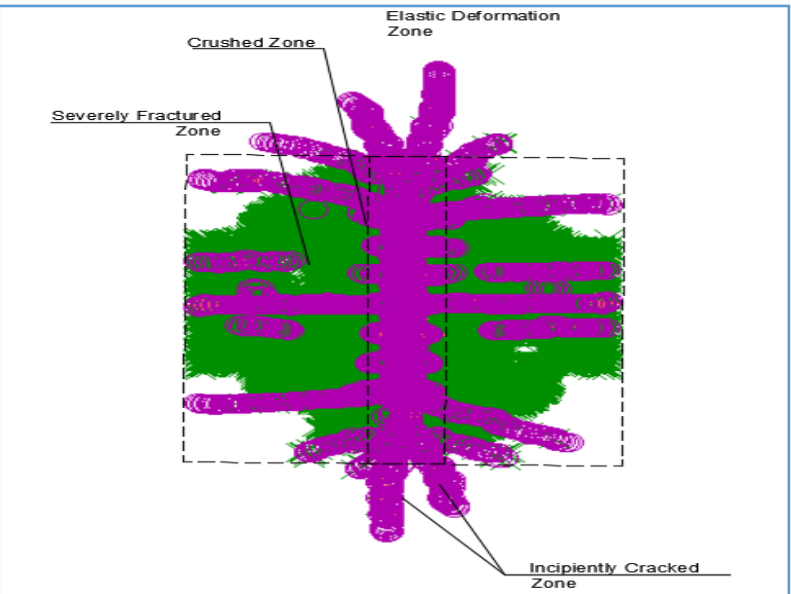

Fig. 10: B) Illustration of Crushed Zone and Severely Fractured Zones Around Blasthole- Case 4: Seven Blasting Points.
The main purpose of the numerical modeling using UDEC is clearly demonstrated in case 4 when seven blasting points were installed, the area of the damaged zone increases with time, and the areas of the crushed zone and the severely fractured zone are the smallest among all the discussed cases.

\subsection{Stress wave \& velocity diagrams}

The figures below represent the stress wave and the velocity maps for each model at $1.6 \mathrm{~ms}$ time-step.

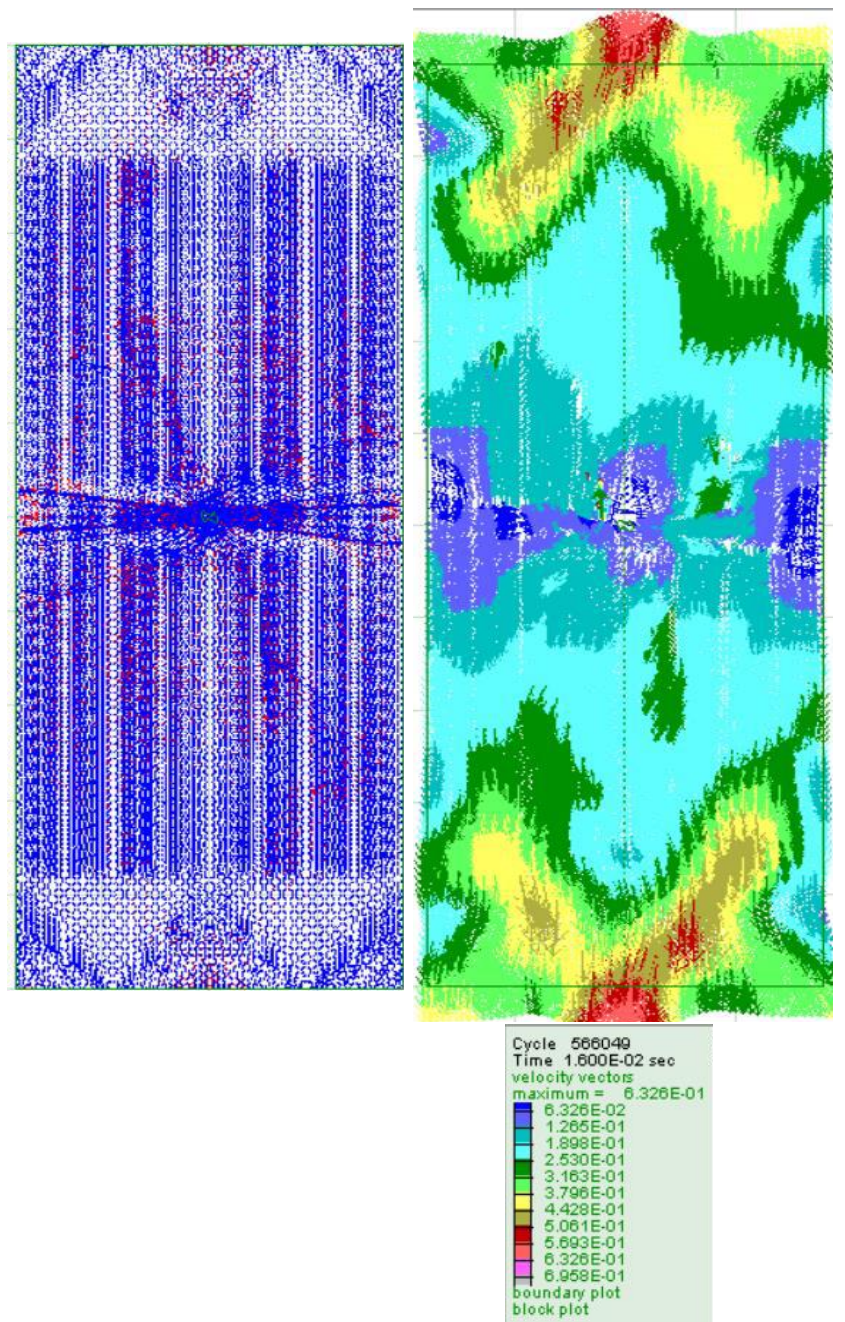

Fig. 11: Stress Wave and Velocity Diagrams at $1.6 \mathrm{~ms}$ - Case 1: One Blasting Point. 


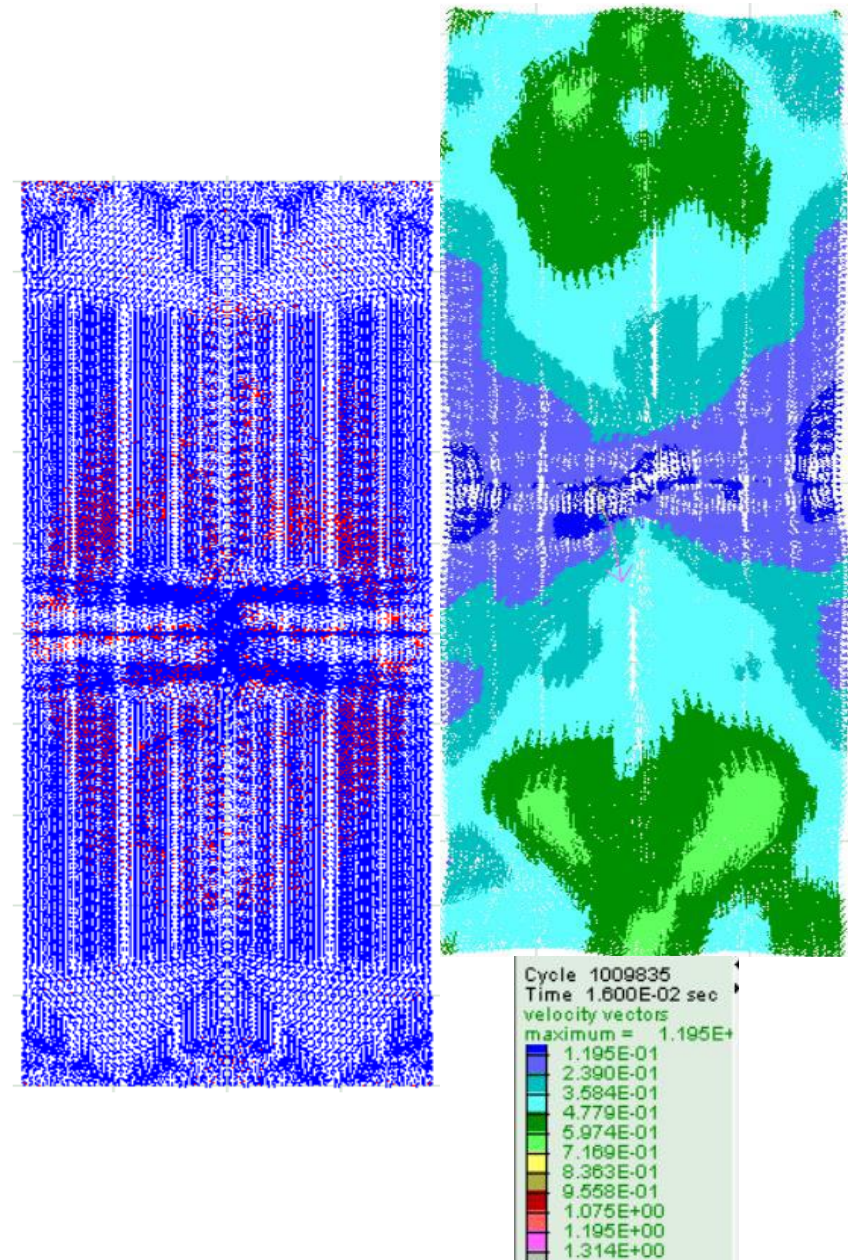

Fig. 12: Stress Wave Front and Velocity Diagrams At $1.6 \mathrm{~ms}$ - Case 2: Three Blasting Points.

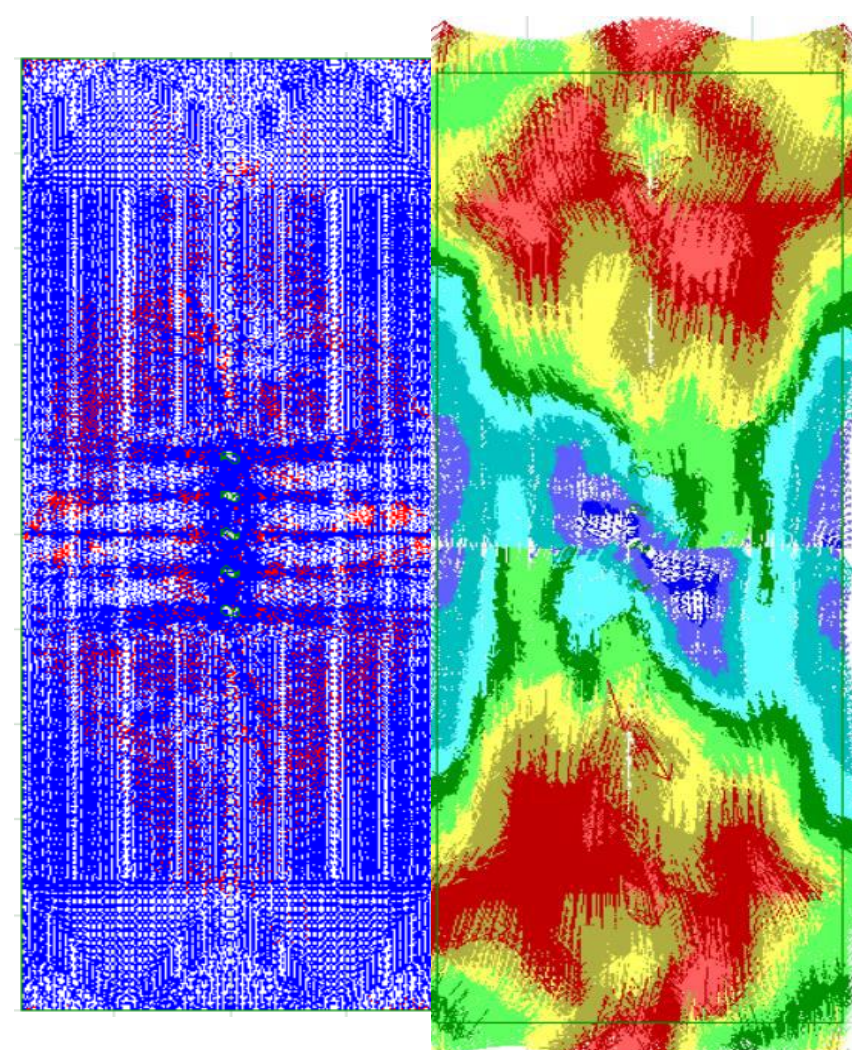

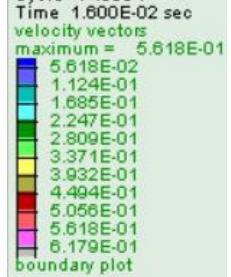

Fig. 13: Stress Wave Front and Velocity Diagrams at $1.6 \mathrm{~ms}$ - Case 3: Five Blasting Points.
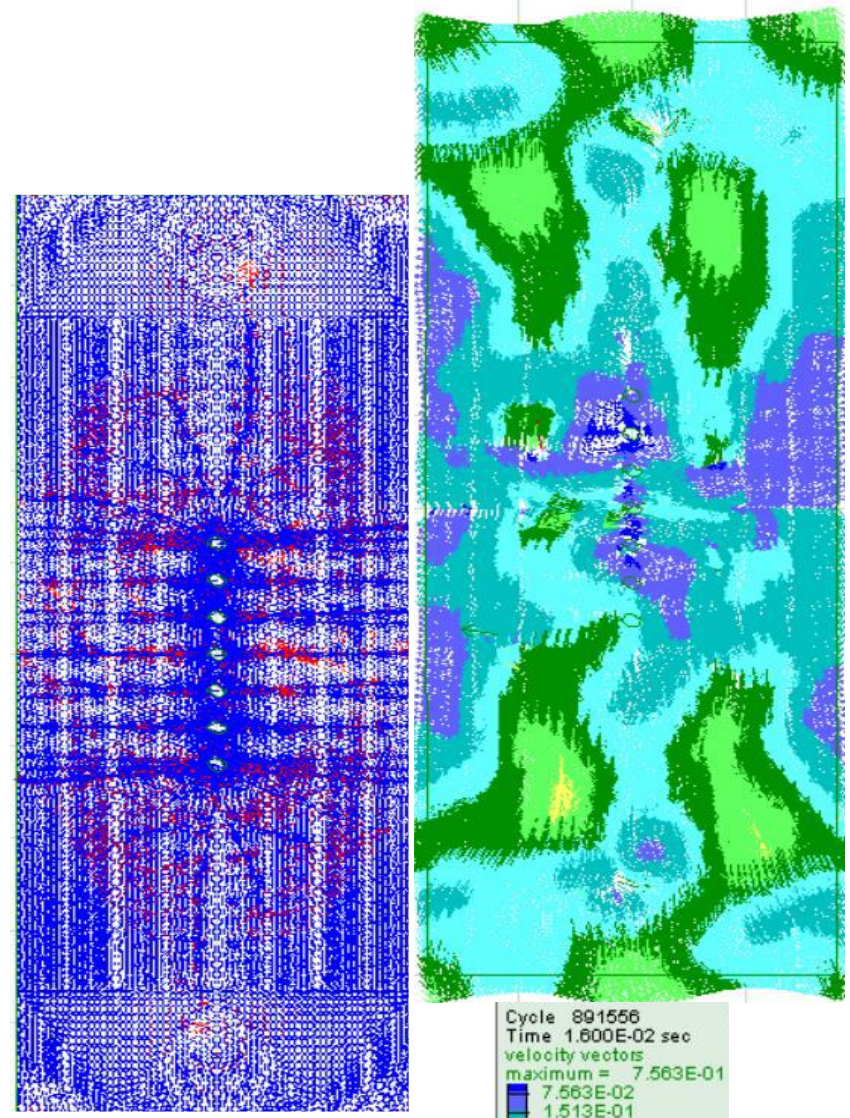

Cyole 891556
Time $1.600 \mathrm{E}-02 \mathrm{sec}$

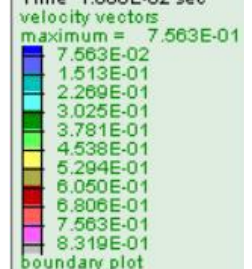

Fig. 14: Stress Wave Front and Velocity Diagrams at $1.6 \mathrm{~ms}$ - Case 4: Seven Blasting Points.

The stress waves and the cracks propagation are clearly outlined in the above figures.

The number of cracks and their lengths increase with the number of blastholes applied despite the decrease of their intensities. Moreover, the maximum explosive's velocity is obtained at the edge of the blasthole.

\section{Conclusion}

The 2D Universal Distinct Element Code (UDEC) was used to study and analyze the behavior of rock masses due to different intensities of blasting knowing that the total intensities for all the simulations are almost similar.

Wave propagation and fracture initiation in the media were plotted for four different models that differ with the number of blasting points and intensity of each.

The numerical modeling shows that the area occupied by the crushed zone and the cracks' propagation are related to the pressure of the blasthole. Hence, the largest area of crushed zone is obtained when one blasthole with the highest intensity is applied, however; 
the largest number of cracks is obtained when seven blastholes are applied.

Since the main objective of this work is to highlight the most suitable method to increase permeability and porosity and hence the productivity rate of oil and gas, it is recommended to use a blasthole line with minimum intensity in order not to damage the site, minimum area of crushed zone, and to obtain larger cracks' propagation.

\section{Acknowledgement}

The authors are grateful to Rafik Hariri University and Lebanese university for their academic, and technical support.

\section{References}

[1] Abdallah Mirvat, Salami Houssam, Overview of the Oil and Gas exploration in Lebanon, in Proceedings of the IEEE, 1st Mediterranean Gas and Oil International Conference (MedGO 2015), pp: 1-4 - April 2015, Beirut, Lebanon

[2] Aliabadian Z., Sharafisafa M., Nazemi M., Simulation of Dynamic Fracturing of continuum rock in open pit mining, Geomaterials, 2013, 3, 82-89. https://doi.org/10.4236/gm.2013.33011.

[3] CEDRO, the National Geothermal Resource Assessment of Lebanon, February 2014

[4] CHO S. H., "A method for estimating the strength properties of a granitic rock subjected to dynamic loading", International Journal of Rock Mechanics and Mining Sciences 42(4):561-568 - June 2005 with 11 Reads https://doi.org/10.1016/j.ijrmms.2005.01.004.

[5] Commercial Explosives and Industrial Chemicals, Pakistan Ordnance Factories.

[6] D. C. Wyliie and C. W. Mah, "Rock Slope Engineering," 4th Edition, Taylor \& Francis, London, 2005.

[7] E. Lopez, "Drilling and Blasting of Rocks," A. A. Balkema, Netherlands, 1997

[8] http://almashriq.hiof.no/ddc/projects/geology/geology-of-lebanon/.

[9] http://www.law.msu.edu/.

[10] http://www.lpa.gov.lb/prequalification\%20results.php.

[11] http://www.dnr.louisiana.gov/assets/TAD/education/BGBB/4/rocks.html

[12] Itasca Consulting Group, Inc. 2014. UDEC, Universal Distinct Element Code. 4th ed. Minneapolis, USA.

[13] www.jim.or.jp.

[14] ws3-er.eng.hokudai.ac.jp.

[15] Zheming Zhu, "Numerical prediction of crater blasting and bench blasting", International Journal of Rock Mechanics and Mining Sciences 46(6):1088-1096 - September 2009 with 303 Reads DOI: 10.1016/j.ijrmms.2009.05.009. https://doi.org/10.1016/j.ijrmms.2009.05.009.

[16] Z. Zhu, H. Xie and B. Mohanty, "Numerical Investigation of Blasting-Induced Damage in Cylindrical Rocks," International Journal of Rock Mechanics and Mining Sciences, Vol. 45, No. 20, 2008, pp. 111-121. https://doi.org/10.1016/j.ijrmms.2007.04.012. 